\title{
A CLINICAL STUDY OF NUTRITIONAL XEROPHTHALMIA AND NIGHT-BLINDNESS
}

\author{
BY \\ J. C. SPENCE, M.D., F.R.C.P. \\ (From the Royal Victoria Infirmary and College of Medicine, \\ Newcastle-on-Tyne.)
}

Amongst the urban population in the industrial districts of northern England there are to be seen occasional cases of night-blindness or xerophthalmia due to diet deficiency. The patients usually come to hospital with the symptom of night-blindness to seek advice from the ophthalmologists, who readily recognize the nature of the disease and give the appropriate treatment without referring them to the physicians. This may in some measure account for the absence of any recent reference to it in this country, for I can find no published records of recent cases apart from those reported from China during the past few years. I do not suggest that China and northern England are unique in this manner, for I believe that the disease is more wide-spread than is commonly believed, and that an appreciation of its early symptoms will lead to its readier recognition by general physicians.

During the past year my colleague, Dr. J. S. Arkle, has given me the opportunity of studying all these cases which have come to his ophthalmological department, where out of a total of 4,100 out-patients there were 17 cases of nutritional night-blindness or xerophthalmia. Getting the clinical material in this way I have had the advantage of having first an expert ophthalmological opinion and report on the cases, and so of avoiding the possible mistake of including in my series patients suffering from night-blindness or corneal ulceration due to causes other than diet deficiency. That the disease was due to a fault in diet was in each case further confirmed by the results of treatment. Careful selection of the clinical material in some such manner is of importance, for after reading some of the accounts of cases which have been published, especially of those in marasmic infants, it is not clear that the diagnosis was fully established, and the condition of corneal ulceration may have been due to causes other than true nutritional xerophthalmia.

The association of night-blindness and diet deficiency was a fact known to the ancients. They even recognized that some cases could be cured by eating liver, and this knowledge is to be found handed down as tribal lore amongst the Esquimaux and other primitive races. But it is only during the past seventy years that this disease has been the subject of careful clinical and experimental studies ; full reference to which is to be found in the papers of Mori $^{1}$, Ross ${ }^{2}$, Bloch $^{3}$, and Blegvad ${ }^{4}$. The chief milestones in the advance of our knowledge were the early clinical descriptions in 1866 of von Græfe and 
Bitot; the extensive clinical investigations of Mori, who saw 1,511 cases of xerophthalmia and 116 cases of keratomalacia in Japan 'rom 1899 to 1902 , and cured them by giving the oil of fishes' liver ; and the more recent experimental and clinical studies of Bloch, McCollum and others. As a result of these it is now generally accepted that the disease is due to a specific diet deficiency, which is probably a lack of sufficient vitamin A.

The symptoms vary according to the gravity of the disease and the age of the patients, but in the order of their appearance and severity they usually are : (1) night-blindness, (2) xerosis conjunctivæ with the characteristic Bitot's spots, and (3) keratomalacia. In young infants the disease appears to advance rapidly to the stage of keratomalacia, in older patients there may be nightblindness without xerophthalmia, but, as Pillat ${ }^{5}$ has shown, all stages may be present in adults, and from my experience even young children may have night-blindness only. It is also generally accepted that the anti-xerophthalmic factor is also the growth factor, and in addition has a specific effect of increasing resistance to certain infections. This view is based on experimental work in rats and other animals, but it is not fully confirmed by clinical observation or experiment, and it is not supported by the results of my own studies.

In most records of this disease attention has been drawn to the singular manner in which it has affected patients of a particular age or at a particular season of the year. Nearly all of Mori's cases were children between the ages of 1 and 5 years, and the Danish cases were nearly all under the age of 12 months. In the 17 cases which I have seen there was no definite age incidence. The youngest patient was 2 years and 1 month, the oldest 54 , but it was chiefly older children and young adolescents who were affected. The actual ages were : $2,2,4,5,8,9,11,12,12,14,14,16,17,21,23,24$ and 54 years. The social conditions were evidently of the poorest. The oldest patient lived alone in a lodging room. The others all came from large families with the parents unemployed, and the average income available for buying food, after deductions for rent heating and insurance had been made, was from 2 to 3 shillings per week per person.

In all the patients above the age of 2 years night-blindness was the first and chief complaint. In 3 cases night-blindness was the only symptom and they had no visible lesions in the conjunctivæ. In the remaining 14 cases there were to be seen the characteristic signs of xerophthalmia in various stages of development. Amongst the boys the matter of most immediate concern was that, as dusk approached, they could not see to compete successfully in play with their companions in the street. In the two youngest patients, both aged 2 years, there was no complaint of night-blindness, and they were brought to the hospital because the parents had noticed the whitish deposit on the scleral conjunctiva. On further examination of these two children in the dusk it was shown that they had some night-blindness, although it had not been noticed by the parents. This suggests that the reason why the disease does not assume such a severe form in adults as in young children is that the adults seek advice earlier for the symptom of night-blindness, and receive curative treatment before further damage is done. 
It is the opaque whitish deposits on the scleral conjunctiva which is the most characteristic sign of the disease. Bitot first described them and they are now known as Bitot's spots (Fig. 1). The conjunctiva itself may be dry and lustreless, and on this the spots have the appearance of foam or of frost on window panes. In size they vary from tiny specks to particles big enough to cover the whole scleral quadrant beyond the cornea. They are firmly attached and wrinkle peculiarly as the eye-ball is moved. In the later stages
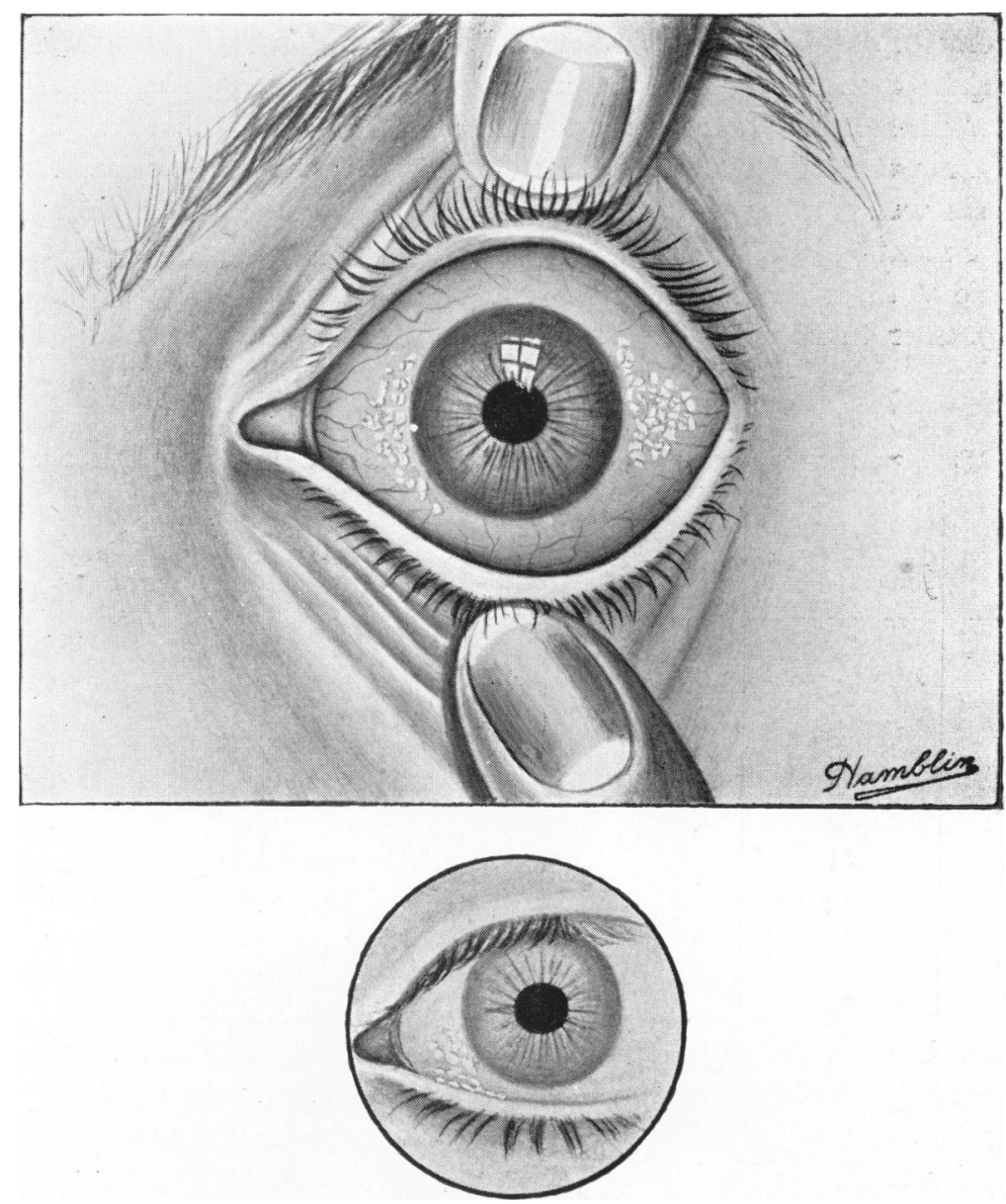

Fir. 1. Appearance of eye in xarophthalmia of moderately severe degree. Bitot's patches on scleral conjunctive. (Drawing supplied by Messrs. Theodore Hamblin Ltd.)

there may be some super-added infection, but in most cases this is absent and the patient feels no discomfort in the eye. In four cases there was early keratomalacia, but in each of these there was also well marked xerosis conjunctivæ with Bitot's spots. I saw no case with corneal damage which did not have these well marked signs in the scleral conjunctivæ, and I should hesitate to diagnose nutritional xerophthalmia where the sole evidence is corneal ulceration without Bitot's spots. 
There was a history of an evidently deficient diet in all cases, with little or no animal fat or meat protein. A close scientific analysis of a diet which has already been eaten is not possible, but enquiry showed that in almost every case it had consisted mainly of wheat flour bread, margarine, jam, vegetables and tea, but of these they had eaten sufficient quantity to satisfy their needs. The deficiency was therefore qualitative, not quantitative. Indeed the amount of bread eaten by some of the boys had been enormous. In no case had milk been drunk apart from the small amount put into tea. A few ounces of meat had been eaten once a week by the majority. Two cases had eaten an egg every day for at least 4 weeks without preventing the onset of the eye symptoms and signs of xerophthalmia. It appears that these eggs at least had no anti-xerophthalmic effect.

There was no definite seasonal incidence in the onset of the disease. Nightblindness was more apparent or became more accentuated in the spring or summer months, but it could not be shown that there was an excess of bright sunshine at those times, and in six cases the symptoms started in the months of December to March. It has been suggested by some observers that the

TABLE 1.

Weights, heIghtS AND h.MOGLOBIN VALUES: NoRMAL FIGURES IN BRACKETS.

\begin{tabular}{|c|c|c|c|c|c|c|}
\hline \multirow{2}{*}{$\begin{array}{c}\text { Case } \\
\text { No. } \\
1\end{array}$} & \multirow{2}{*}{$\frac{\begin{array}{c}\text { Age } \\
\text { (years) }\end{array}}{2}$} & \multicolumn{2}{|c|}{$\begin{array}{l}\text { Weight } \\
\text { (pounds) }\end{array}$} & \multicolumn{2}{|c|}{$\begin{array}{l}\text { Height } \\
\text { (inches) }\end{array}$} & \multirow{2}{*}{$\begin{array}{c}\begin{array}{c}\text { Hb. \% } \\
\text { (Sahli) }\end{array} \\
45\end{array}$} \\
\hline & & $19 \frac{1}{2}$ & $(27)$ & 31 & $(34)$ & \\
\hline 2 & 21 & 26 & $(29)$ & $33 \frac{1}{2}$ & $\left(35 \frac{1}{2}\right)$ & 72 \\
\hline 3 & 4 & 374 & $(35)$ & 31 & $(40)$ & - \\
\hline 4 & 5 & 44 & (42) & 42 & $(42)$ & 80 \\
\hline 5 & 8 & $54 \frac{1}{2}$ & $(5 \tilde{5})$ & 48 & $\left(48 \frac{1}{2}\right)$ & 85 \\
\hline 6 & 9 & $50 \frac{3}{4}$ & $(57)$ & $46 \frac{1}{2}$ & $(49)$ & 65 \\
\hline 7 & 11 & 51 & (69) & 50 & (53) & 一 \\
\hline 8 & 12 & 84 & (80) & 5.5 & (56) & 92 \\
\hline 9 & 12 & 72 & $(80)$ & 56 & $(56)$ & 74 \\
\hline \multirow[t]{2}{*}{10} & 14 & 87 & $(100)$ & 59 & (61) & 60 \\
\hline & & & & & & \\
\hline
\end{tabular}

seasonal incidence of night-blindness is partially to be explained by the extra strain of bright sunshine in the summer months amongst people who are already living on a border-line deficient diet, but the circumstances of two cases proved that this was more probably due to the physical exertion of extra work at that time. These were boys of 16 and 17 years. They complained of night-blindness and xerophthalmia with Bitot's spots. The first symptoms had appeared in the months of July and August, but in each case they had started heavy physical work in a coal mine a few weeks before the first symptoms appeared, and being underground most of the day had had little opportunity of being exposed to bright sunshine. Their diet was typical of that likely to produce xerophthalmia, and had been so for many months before they started working in the pits. Thus it appeared that in these cases the precipitating factor was extra physical exertion and not sunshine. 
On measurement most of the patients were only slightly below the ideal standards in height and weight, and the general condition and appearance was that of fairly robust health (Fig. 2). The youngest child, aged 2, alone looked at all ill. He weighed $19 \mathrm{lb} .8 \mathrm{oz}$., had a hæmoglobin of 45 per cent., could not walk, and resembled the type described by Bloch as 'carbohydrate dystrophy.' All others had the appearance of well nourished active looking people. In Table 1 are given the actual weights, heights and hæmoglobin

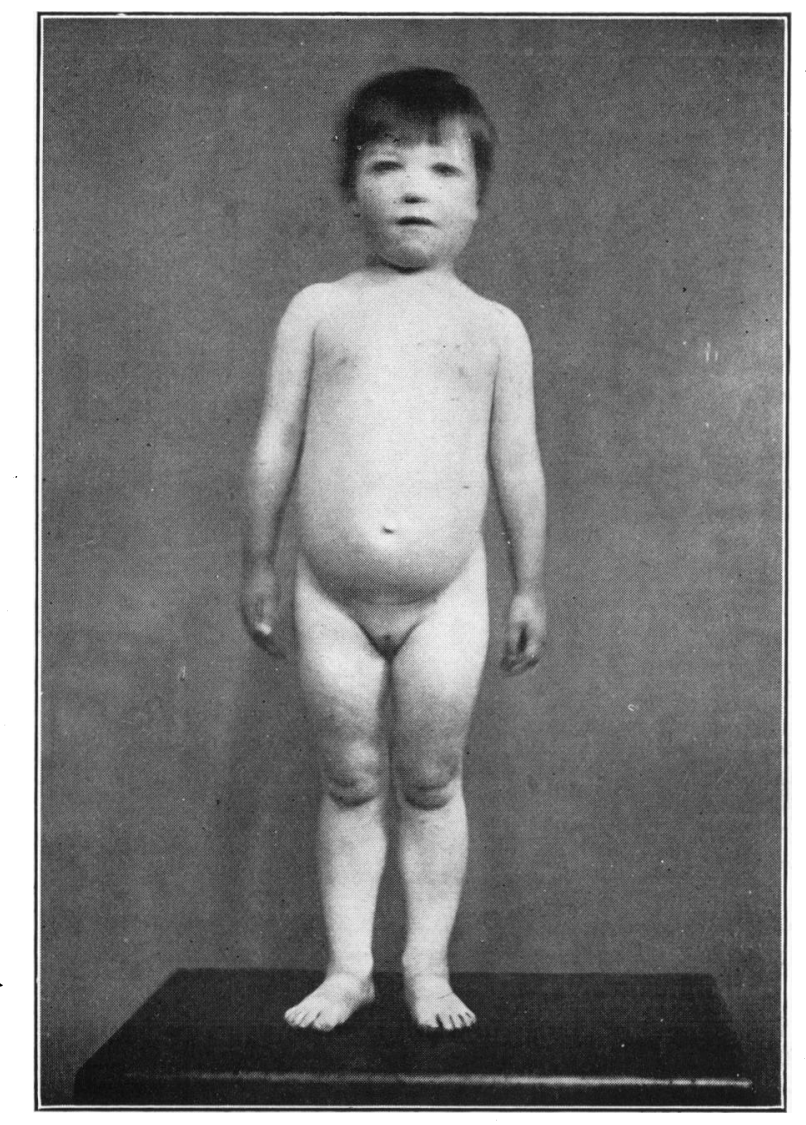

FId. 2. Child of 2 years and 11 months-with recurrent xerophthalmia for more than 6 months. Bitot's suots in all iour quadrants of scleral conjunctive. Showing good general condition. Weight $30 \mathrm{lb}$. (normal $32 \mathrm{lb}$.). Height $35 \frac{1}{2}$ inches (normal $36 \frac{1}{2}$ inches).

values of the ten youngest patients, and it will be seen that there is no great divergence from the usual type of hospital patient. There was one prominent symptom, however, of which all the older patients complained, and that was lassitude. It appeared to be a common accompaniment of the disease, and disappeared quickly under treatment. Apart from this and the eye signs there were no other special symptoms. 
At this point I may mention the result of treatment in so far as it affected the rate of growth of the patients. There was no striking rise of height curves coincident with the cure of the xerophthalmia such as occurs in experimental animals on a diet deficient in vitamin-A when given curative diet.

Fig. 3 refers to a case of a boy who had had symptoms of xerophthalmia for 6 months and had been on a poor diet for some time before that. Butter and milk were added to his diet and he was given $30 \mathrm{c.cm}$. of cod-liver oil daily. There was a very rapid cure of his xerophthalmia without any immediate increase in weight or height. The extra diet was continued for 10 months while he was kept closely under observation, and the increase in weight and size was not greater than that expected in a normal boy of his age.

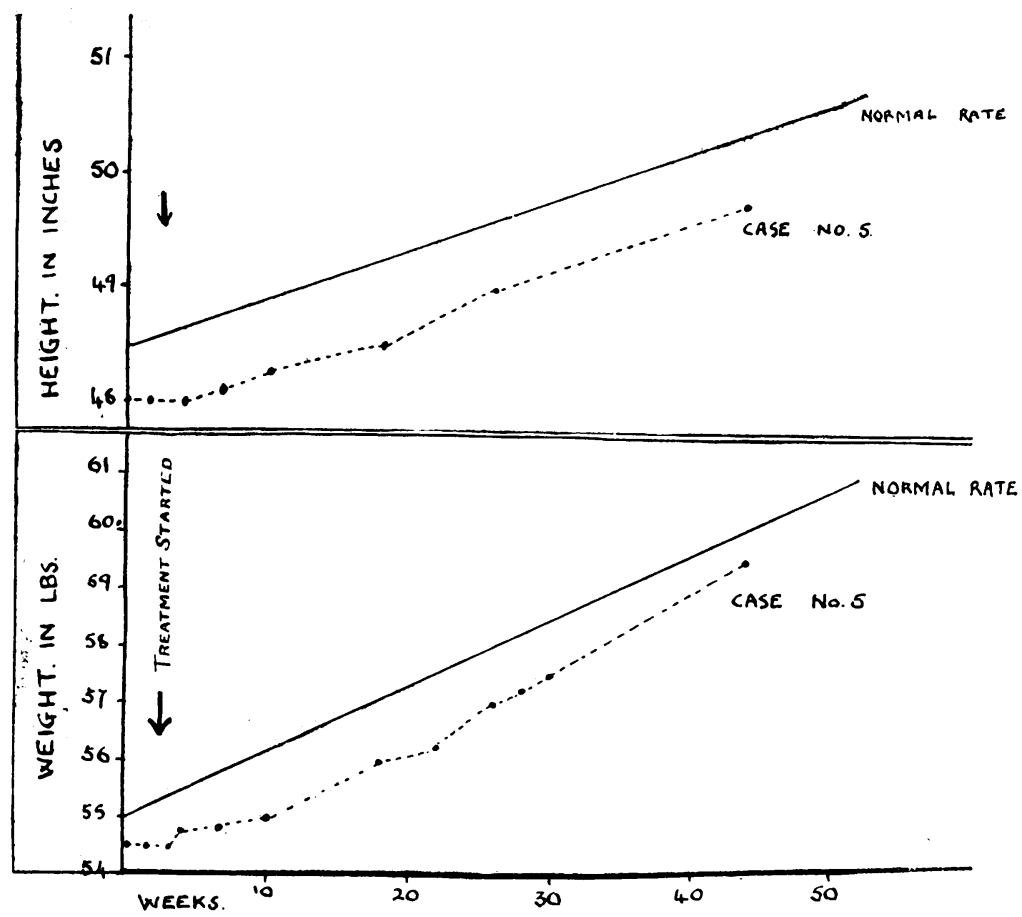

Fra. 3. Height and weight charts during treatment with cod liver oil, butter and miln. Boy of 8 , with symptoms of xerophthalmia for 9 months. Had been on deficient diet for at least 2 years.

The following is another example of a boy showing rapid cure of his xerophthalmia without any increase in the rate of growth :-

A boy aged 11. The third member of a family of 7 children living in 2 rooms. Father out of work for 3 years. Total weekly income 32 shillings, with 17 shillings spent on rent, insurance, coal and clothing club, leaving 15 shillings for food. The diet was a typically deficient diet and had been so for at least 2 years. Boy attended hospital on account of night-blindness. Typical Bitot's spots on scleral conjunctiva. On Sept. 25th, 1929, weight 51 lb., height 50 inches. He was then treated with $60 \mathrm{c.cm}$. of cod-liver oil daily and extra butter in the diet. There was a rapid improvement in the night-blindness and complete disappearance of Bitot's spots in 4 weeks. The cod-liver oil and butter were continued for 6 months, when (on March 5th, 1930,) the weight was $56 \mathrm{lb}$., height 50 inches. He gained $5 \mathrm{lb}$. in weight without increase in height. 
These results show that it is possible to have a form of diet deficiency which will produce xerophthalmia without affecting the general health or growth of the patient.

Relation of xerophthalmia to rickets and other deficiency diseases.All cases under the age of 12 were carefully examined clinically and radiographically for signs of rickets. both before and after treatment. In no case was there any evidence of active rickets. In three cases aged $2 \frac{1}{2}, 4$ and 12, blood-calcium and phosphorus estimations were also done. The results fell within normal limits and were not altered by treatment and the cure of the xerophthalmia. The values found are given in Table 2.

There were no signs of scurvy, beri-beri, pellagra or œdema in any case. This absence of other deficiency diseases has been confirmed by the recent observations of Weech ${ }^{6}$, and reveals the truly specific character of the diet deficiency causing xerophthalmia.

TABLE $\stackrel{2}{-}$

Blood analyses in three cases of xerophthalma.

\begin{tabular}{c|c|c|c|c}
\hline $\begin{array}{c}\text { (ase } \\
\text { No. }\end{array}$ & $\begin{array}{c}\text { Age } \\
\text { Years }\end{array}$ & Date & $\begin{array}{c}\text { Serum calcium } \\
\text { mgrm. per 100 c.cm. }\end{array}$ & $\begin{array}{c}\text { Plasm. p.iosp.iorus } \\
\text { mgrm. per 100 c.cm. }\end{array}$ \\
\hline 2 & $2 \frac{1}{2}$ & $14 / 8 / 29$ & $9 \cdot 6$ & $4 \cdot 0$ \\
& & $11 / 9 / 29$ & $9 \cdot 8$ & $3 \cdot 8$ \\
4 & 4 & $12 / 6 / 29$ & $10 \cdot 2$ & $2 \cdot 7$ \\
- & 12 & $18 / 6 / 30$ & $10 \cdot 0$ & $2 \cdot 8$ \\
& & $2 / 7 / 30$ & $9 \cdot 7$ & $2 \cdot 6$ \\
\hline
\end{tabular}

Relation of xerophthalmic diet and resistance to infection.--It has been claimed by Mellanby ${ }^{2}$ and others that vitamin $\mathrm{A}$ has a preventive effect against and curative influence on general infections, especially of the streptococcal group.

With this in view an investigation of the general health and incidence of disease in the families of the 11 youngest patients was carried out. All these families were fairly large, and the total number of parents and children was 99. All of these had eaten approximately the same type of diet. Over a period of two years the only serious febrile illnesses in these families were one case of pneumonia in a girl of 14 who died, two cases of mumps and three of measles with complete recovery. This does not constitute an excessive incidence of infectious disease in a group of people living on a xerophthalmia, producing diet. There was, however, a very high incidence of skin sepsis, impetigo and boils. Of the 11 xerophthalmic children 7 had a history of indolent skin sepsis which was cured remarkably quickly by anti-xerophthalmic treatment.

It is now known from the results of the pathological researches of Wolbach and Howe ${ }^{8}$ and Tyson and Smith ${ }^{9}$ that the most characteristic tissue change 
which results from vitamin A deficiency is to be found in epithelial structures. This is a hyperplasia and then a metaplasia of cuboidal or columnar epithelium which goes on to keratinization, especially in the renal tract, air passages and salivary glands. No doubt the tendency to skin sepsis in xerophthalmia is connected with this, and is an expression of this alteration which takes place in epithelial tissues. In my cases there was other clinical evidence confirming this, namely the number of epithelial cells in the urine. I am fully aware of the apparently fortuitous manner in which bladder and renal pelvis cells may' appear in the urine under various conditions, and without there being any deficiency in the diet. But in the cases severely affected with xerophthalmia the number of epithelial cells and their persistence until treatment was given was most striking. In two cases who had night-blindness alone, without xerophthalmia, there were only a scanty number which could not be regarded as abnormal. This skin sepsis and epithelium shedding into the urine must be regarded as a result of xerophthalmia-producing diet deficiency, for they both reacted to treatment with xerophthalmia-curing substances such as butter and cod-liver oil.

\section{Results of treatment.}

Some of the cases were chosen for a preliminary study of the maximum rate of cure by adding large amounts of cod-liver oil, butter and milk to the diet, so that they might be used for a basis of comparison in the trial of other forms of treatment. The first two cases were admitted to hospital for this, but it was found that although they were at first kept for a preliminary period on an experimental diet of skimmed milk, bread, margarine and jam, a rapid cure took place. It was apparently difficult to prevent a cure of the xerophthalmia as soon as any alteration from their original diet was made, even although it was attempted to keep it free from vitamin-A. It was then decided to treat subsequent cases as out-patients without revealing to them that their eye symptoms were due to a diet deficiency. In this way they continued to eat at home the same deficient diet as before, with extras which were provided for them. Thus it was possible to try the effect of such substances as ergosterol and liver extract, and of exposure to ultra-violet light, while the existing standard conditions of diet and habits were maintained.

In those cases treated with large amounts of cod-liver oil, butter and milk, the stages of cure were well defined. The first change was an improvement in the night-blindness. This was noted on the third to fifth days, and in from 7 to 14 days the vision was apparently normal. In the case of the children this could be judged by the readiness with which they returned to play with their companions in the streets at dusk. Towards the end of the first week the Bitot's spots on the scleral conjunctiva began to become more fragmented and to decrease in size, and in the severest cases had disappeared completely by the fifth or sixth week. After the disappearance of the spots some xerosis of the conjunctiva giving a characteristic lustreless appearance remained for a further 10 to 15 days. In all cases which were given adequate treatment all signs and symptoms had disappeared within two months. From this it was 
accepted as a standard rate of cure that night-blindness would begin to improve within a week, and that a disappearance of the Bitot's spots would commence within two weeks, and that all signs would have disappeared within two months.

One case was treated by the addition of only 15 c.cm. of cod-liver oil daily to his diet, and another of $10 \mathrm{c.cm}$. daily. In both of these there was definite improvement of the night-blindness within a week, and complete disappearance of it within three weeks. The rate of cure of the xerosis was almost as rapid as in those cases treated with large amounts of cod-liver oil and butter.

In two cases irradiated ergosterol (radiostol) was used as treatment without any alteration in the diet. In one case 4 tablets a day were given, in the other case 12 tablets. The treatment was continued for three weeks without any improvement in the night-blindness. Thus it was judged to have no antixerophthalmic effect. There was, however, one result of this treatment with irradiated ergosterol which deserves mention. That was the complete and rapid disappearance of weaknc:s and lassitude which is so frequently present in this type of diet deficiency. One of the patients, a young adult of 21 , was an excellent witness and he volunteered the statement of feeling a remarkable improvement in his strength with complete disappearance of lassitude within two weeks, although there was no improvement in his night-blindness o.I xerosis conjunctivæ.

One case was treated with dried liver extract, effective in pernicious anæmia. He was a boy of 12 who had had intermittent night-blindness for two years. He had attended a doctor who prescribed eye lotions without giving advice on his diet. Weight $72 \mathrm{lb}$. and height 56 inches. There was a definite xerosis with Bitot's patches in all four quadrants of the scleral conjunctiva. He was given liver extract for three weeks equivalent to $\frac{1}{2} \mathrm{lb}$. of fresh liver a day. There was no improvement for two weeks. In the third week the boy stated he could see a little better at night, but the mother stated she did not think he had improved as he still stumbled over the chairs in the dusk, and had not yet joined the other children in their games in the streets. 'The xerosis and Bitot's spots were unchanged. It was judged that this pernicious-anæmia-curing liver extract had no anti-xerophthalmic effect.

One case was treated by daily exposure to mercury-vapour-lamp irradiation for four weeks, without any alteration in the diet. This had no curative effect.

\section{Summary.}

My investigation shows that nutritional night-blindness and xerophthalmia occurs sporadically in an urban industrial population, but that although large numbers of people are apparently living on the same type of deficient diet, it is only a few that become affected by the disease.

The disease was found to occur even in children whose general condition and rate of growth had been well maintained; and cure of the disease by a high vitamin diet did not necessarily result in a coincident rise in weight or height. 
There was no evidence of rickets or other deficiency diseases in the affected cases.

There was a high incidence of skin sepsis amongst the cases. In the active stage of the disease there are large numbers of epithelial cells in the urine. This is a clinical confirmation of Wolbach and Howe's pathological discovery that the most specific tissue change in vitamin-A deficiency is a debasement and damage of epithelial structures.

Apart from this skin sepsis there was no evidence of a lowered resistance to general infections in people living on a xerophthalmia-producing diet.

A maximum rate of cure was studied. Using this as a basis it was shown that irradiated ergosterol, ultra-violet irradiation and pernicious-anæmiacuring liver extract have no curative effect on xerophthalmia, and that cases of xerophthalmia can be cured by adding as little as $10 \mathrm{c.cm}$. of cod-liver oil to the diet daily.

\section{REFERENCES,}

1. Mori, M., Jahrb. f. Kind., Berlin, 1904, LV, 175.

2. Ross, S. G., Am. J. Dis. Ch., Chicago, 1921, XXII, 232.

3. Bloch, C. E., J. Hyg., Lond., 1921, XIX, 283, \& Jahr.f. Kind., Berlin, 1919, LXXXIX, 405.

4. Blegvad, O., Am. J. Ophth., Chicago, 1924, VII, 89.

5. Pillat, A., Arch. Ophth., N.Y., 1929, II, 256.

6. Weech, A. A., Am. J. Dis. Ch., Chicago, 1930, XXXIX, 1153.

7. Mellanby, E., \& Green, H. N., Brit. Med. J., Lond., 1929, i, 984.

8. Wolbach, S. B., \& Howe, P. R., Proc. Soc. Exp. Biol. \& Med., N.Y., 1924-25, XXII, 402.

9. Tyson, M. D., \& Smith, A. H., Am. J. Path., Boston, 1929, V, 57. 